\title{
Transcriptional profiling of the nucleus pulposus: say yes to notochord
}

\author{
Irving M Shapiro* and Makarand V Risbud* \\ See related research by Minogue et al., http://arthritis-research.com/content/12/1/R22
}

\begin{abstract}
This editorial addresses the debate concerning the origin of adult nucleus pulposus cells in the light of profiling studies by Minogue and colleagues. In their report of several marker genes that distinguish nucleus pulposus cells from other related cell types, the authors provide novel insights into the notochordal nature of the former. Together with recently published work, their work lends support to the view that all cells present within the nucleus pulposus are derived from the notochord. Hence, the choice of an animal model for disc research should be based on considerations other than the cell loss and replacement by nonnotochordal cells.
\end{abstract}

Despite many concerns, profiling has been used successfully to identify or predict possible antisocial behaviors. Profiling relies on highlighting unique traits against a background of confounding signals. Similarly, transcriptional profiling is a powerful technique to determine marker genes that characterize and distinguish a particular cell type. In a recent issue of Arthritis Research \& Therapy, Minogue and colleagues [1] used transcriptional profiling to examine the phenotypic characteristics of bovine intervertebral disc cells and provided some novel insights into the current debate concerning the origin of cells of the adult nucleus pulposus. One aspect of this ongoing controversy is whether the onset of degenerative disc disease is due to the loss of the original notochordal cells or to the replacement of them by unrelated cell types or to both [2]. This dispute affects investigational strategies in which the choice of animal model for a study is governed by the consideration of whether notochordal cells are present in the disc or have been replaced by cells

*Correspondence: irving.shapiro@jefferson.edu or makarand.risbud@jefferson.edu Department of Orthopaedic Surgery, Jefferson Medical College, 1015 Walnut Street, Suite 501, Curtis Building, Philadelphia, PA 19107, USA that are non-notochordal in origin [3]. The focus of this editorial is to address these long-standing arguments in the light of the profiling studies and work of other investigators. Minogue and colleagues [1] report the identification of a number of marker genes that distinguish nucleus pulposus cells from those of the annulus fibrosus cells and cartilage (chondrocytes). The authors document differential expression of 49 disc-specific and 34 nucleus pulposus-specific genes. The presence of a number of these genes provides a new understanding of the origin of the nucleus pulposus in relationship to the notochord.

Notochordal cells have been reported to be present in the nucleus pulposus in young animals, including humans $[2,4]$. It has also been proposed that most of these cells gradually disappear during aging $[2,4]$ and are replaced by endplate chondrocytes or inner annulus fibrosus cells [5]. In humans, notochordal cells are rarely observed after the age of puberty [4], although a few studies allude to their existence well into maturity [6,7]. These observations raise the question, is there cellular heterogeneity in the nucleus pulposus? To address this question, Choi and colleagues [8] generated fate maps of notochordal cells using tamoxifen-inducible ShhCreERT2 mice. These studies showed unequivocally that the entire cell population of the nucleus pulposus, even in the adult, was descended from the notochord. Another invaluable marker of the ontology of the cells of the nucleus pulposus is the T-box gene brachyury, which is required for differentiation and survival of the notochord [9]. Similarly to profiling studies of rodents and canines, the study by Minogue and colleagues [1] indicated that cells present in the nucleus pulposus of adult bovine as well as human discs express brachyury and cytokeratins 8, 18, and 19 , genes that are present in the notochord $[10,11]$. If it is assumed that the notochordal cells are lost from the disc early in life in these species, then these results are unexpected. A more acceptable explanation is that the nucleus pulposus is populated by notochordal cells. Minogue and colleagues [1] showed, in direct relevance to this finding, that the large notochordal and small chondrocyte-like nucleus pulposus cells in bovine disc have substantially overlapping gene expression profiles, 
including that of brachyury. These findings are in accord with a recent observation that the rabbit notochordal cells can differentiate into cells of different morphologies not unlike those that are seen in the disc [12]. Interestingly, it was reported that with degeneration of the human nucleus pulposus, mRNA expression of brachyury remained unchanged whereas cytokeratins 8 and 18 are decreased [1]. This finding speaks to the value of brachyury as a nucleus pulposus marker and suggests that the disc retains notochordal cells throughout adult life, even during degeneration, and that the two cell types may have a common lineage.

It should also be pointed out that the results of Minogue and colleagues [1] differ from those of Gilson and colleagues [13], who have reported that the expression of cytokeratin 8 was restricted to a small cohort of cells (described as notochordal) in the adult bovine nucleus pulposus. Surprisingly, these cells were similar in size to the chondrocyte-like cells of the nucleus pulposus and unlike the large notochordal cells isolated by Minogue and colleagues [1]. To explain these conflicting results, it would be critical to extend their studies in two directions. First, it would be critical to confirm the expression of identified marker genes in the morphologically distinct cell types by means of immunohistochemistry, flow cytometry, and Western blot analysis. Second, the microarray profiling studies need to include cells from normal and degenerate human discs. While all investigators are cognizant of the difficulties of obtaining a human control tissue that is valid, it is critical that minimally compromised discs not be accepted as a control.

The implication of the study by Minogue and colleagues affects disc research endeavors, especially those that require the use of animal models. There is no strong experimental evidence to support the view that, in mature animals, the nucleus pulposus recruits cells from the endplate or annulus fibrosus and by inference that all of these cell types are derived from different lineages. Models of small and large animals share a commonality in terms of notochordal gene profiles and therefore nucleus pulposus cell composition and lineage. On the basis of these findings, the most critical choice of an animal model for investigation should be based on anatomical and mechanical considerations of the spinal unit rather than on concerns of cell loss and replacement by non-notochordal cells.

Competing interests

The authors declare that they have no competing interests.

\section{Acknowledgments}

This work was supported by National Institutes of Health grants R01-AR050087 and R01-AR055655.

Published: 20 May 2010

\section{References}

1. Minogue BM, Richardson SM, Zeef LA, Freemont AJ, Hoyland JA: Transcriptional profiling of bovine intervertebral disc cells: implications for identification of normal and degenerate human intervertebral disc cell phenotypes. Arthritis Res Ther 2010, 12:R22.

2. Hunter CJ, Matyas JR, Duncan NA: The notochordal cell in the nucleus pulposus: a review in the context of tissue engineering. Tissue Eng 2003, 9:667-677.

3. Alini M, Eisenstein SM, Ito K, Little C, Kettler AA, Masuda K, Melrose J, Ralphs J, Stokes I, Wilke HJ: Are animal models useful for studying human disc disorders/degeneration? Eur Spine J 2008, 17:2-19.

4. Walmsley R: Development and growth of the intervertebral disc. Edinburgh Med J 1953, 60:341-363.

5. Kim KW, Lim TH, Kim JG, Jeong ST, Masuda K, An HS: The origin of chondrocytes in the nucleus pulposus and histologic findings associated with the transition of a notochordal nucleus pulposus to a fibrocartilaginous nucleus pulposus in intact rabbit intervertebral discs. Spine 2003, 28:982-990.

6. Stosiek P, Kasper M, Karsten U: Expression of cytokeratin and vimentin in nucleus pulposus cells. Differentiation 1988, 39:78-81.

7. Trout JJ, Buckwalter JA, Moore KC: Ultrastructure of the human intervertebral disc: II. Cells of the nucleus pulposus. Anat Rec 1982, 204:307-314.

8. Choi KS, Cohn MJ, Harfe BD: Identification of nucleus pulposus precursor cells and notochordal remnants in the mouse: implications for disk degeneration and chordoma formation. Dev Dyn 2008, 237:3953-3958.

9. Herrmann BG, Kispert A: The T genes in embryogenesis. Trends Genet 1994, 10:280-286.

10. Lee CR, Sakai D, Nakai T, Toyama K, Mochida J, Alini M, Grad S: A phenotypic comparison of intervertebral disc and articular cartilage cells in the rat. Eur Spine J 2007, 16:2174-2185.

11. Sakai D, Nakai T, Mochida J, Alini M, Grad S: Differential phenotype of intervertebral disc cells: microarray and immunohistochemical analysis of canine nucleus pulposus and anulus fibrosus. Spine 2009, 34:1448-1456.

12. Kim JH, Deasy BM, Seo HY, Studer RK, Vo NV, Georgescu HI, Sowa GA, Kang JD: Differentiation of intervertebral notochordal cells through live automated cell imaging system in vitro. Spine 2009, 34:2486-2493.

13. Gilson A, Dreger M, Urban JP: Differential expression levels of cytokeratin 8 in cells of the ovine nucleus pulposus complicates the search for specific intervertebral disc cell markers. Arthritis Res Ther 2010, 12:R24.

doi:10.1186/ar3003

Cite this article as: Shapiro IM, Risbud MV: Transcriptional profiling of the nucleus pulposus: say yes to notochord. Arthritis Research \& Therapy 2010, 12:117. 